\title{
Melatonin in Pain Modulation: Analgesic or Proalgesic?
}

\author{
Yongliang Liu ${ }^{1,2}$, Hongwen $\mathrm{He}^{1,2 *}$, Fang Huang1,2* \\ ${ }^{1}$ Guanghua School of Stomatology, Hospital of Stomatology, Sun Yat-sen University, Guangzhou, China \\ ${ }^{2}$ Guangdong Provincial Key Laboratory of Stomatology, Guangzhou, China \\ Email: ${ }^{*}$ hehw@mail.sysu.edu.cn, ${ }^{*}$ gzhfang@yahoo.com.cn
}

Received 10 January 2014; revised 22 February 2014; accepted 20 March 2014

Copyright $(02014$ by authors and Scientific Research Publishing Inc.

This work is licensed under the Creative Commons Attribution International License (CC BY). http://creativecommons.org/licenses/by/4.0/

(c) () Open Access

\begin{abstract}
Melatonin, as an endogenous hormone produced mainly in the pineal gland in a clear circadian fashion, has diverse physiological functions, such as the control of circadian rhythms, sleep regulation, antioxidant, etc. Recently, accumulating researches about melatonin and pain have been reported. In this review, comparison and summary about analgesic/proalgesic effect of melatonin in inflammatory and neuropathic pain will be made. Some possible pathways of melatonin involved in dual pain modulation might help to explain all these conflicting results in various situations.
\end{abstract}

\section{Keywords}

Melatonin, Pain, Modulation, Analgesic, Pro-Algesic

\section{Introduction}

Pain was described as "an unpleasant sensory and emotional experience associated with actual or potential tissue damage". Hyperalgesic (higher reaction to nociception) and allodynia (pain due to a stimulus that does not normally provoke pain) always accompanied with inflammatory and chronic pain. As an almost ubiquitous phenomenon in all medical conditions, its management has great clinical importance [1].

Melatonin (N-acetyl-5-methoxytryptamine) is a remarkable neurohormone molecule produced mainly in the pineal gland in a clear circadian fashion, exhibited a remarkable functional versatility like the control of circadian rhythms, sleep regulation, antioxidant, and so on [2]. Among them, its nociceptive effect has drawn ample attentions for its potency to be a promising analgesic.

Melatonin receptors are important mediator of its many physiological and pharmacological actions. There are two membrane-associated melatonin binding sites: ML1 and ML2 according to different affinities. In mammals,

*Corresponding author. 
ML1 includes two high affinity G-protein coupled membrane receptors (MT1, MT2). Relative low affinity nuclear receptors (RZR/ROR) and calmodulin belonged to ML2 [2] [3]. Earlier studies found that melatonin receptors are present in various areas of the brain such as the thalamus, hypothalamus, spinal trigeminal tract and trigeminal nucleus [4]. It has been reported that melatonin receptors distribute in lamina I - V and/or lamina X of the spinal cord that are involved in the pain regulatory mechanisms followed a species-dependent mammer [5] [6]. Moreover, Zahn et al. [7] proved that in rat, MT1 and MT2 melatonin receptors are present in ventral and dorsal horn of thoracic and lumbar regions of the spinal cord. And MT1 receptor is the major one.

Rat and mice are the most common experimental animals. Common models include: inflammatory pain (such as formalin injection) [8]-[10], neuropathic pain (like sciatic nerve ligation) [11]-[13] and acute pain (like hotplate text) [14]. It should be noted that different pain tests draw conflicting conclusions. As Perissin et al. [14] reported that in the hotplate test in mice, pain threshold (paw-lick latency) was lower in the morning while pain tolerance (escape latency) was higher. Most animal experiments supported analgesic effect of melatonin [8] [12] [13], but there were still different voices [9]. Animal experiments suggested an analgesic effect of endogenous melatonin [15] [16], while controversy appeared when comes to human [17].

Clinical experiments mainly focus on fibromyalga, inflammatory bowel syndrome and migraine. The majority of them support that exogenous melatonin eases pain, improve sleep and depression [18]. Interesting, Balahan Makay [19] reported that abnormal high melatonin level might cause a disease called growing pain.

\section{Melatonin in Inflammatory and Neuropathic Pain}

Inflammatory and neuropathic pain, represent clinical pain in different conditions [20]. As two common experimental models to study pain modulatory effect of melatonin, vast researches had been carried on.

\subsection{Melatonin in Inflammatory Pain}

Formalin test, as a model of tonic nociception, allows quantifying pain responses integrated at supraspinal and spinal levels, such as paw licking and flinching, in comparison with nonspecific behaviors such as self-grooming and locomotor activity [21]. It was biphasic: the initial acute phase $(0-10 \mathrm{~min})$ was followed by a relatively short quiescent period, which was then followed by a prolonged tonic response (15 - $60 \mathrm{~min})$ [14].

Perissin et al. [9] reported that in mice, higher nociceptive responses at dark period comparing to lightperiod, while melatonin antagonist luzindole and functional pinealectomy were able to reverse this phenomena.Also more melatonin binding sizes at light period than dark period, suggested a pro-analgesic effect of endogenous melatonin. Wan et al. [6] also reported that a circadian shift of melatonin binding sites on rabbit spinal cord and maximum number of binding sites in the midlight period. Moreover, Huang et al. [22] showed specific distribution of MT1 in trigeminal ganglion (TG) and caudal spinal trigeminal nucleus (Spc). And in Spc, a downregulation of MT-1 expression was observed during early inflammatory pain. In contrast, Ray et al. [8] reported that in mice, melatonin dose-dependently decreased the licking response in both phases, effect being more remarked in the late phase.ML2 antagonist prazosin attenuated this effect at low dosage $(0.5 \mathrm{mg} / \mathrm{kg})$ while did the opposite at high dosage $(1 \mathrm{mg} / \mathrm{kg})$. The author thought it might be caused by activating different receptors: ML2 and $\alpha_{1^{-}}$ adrenoceptor. 5HT3 antagonist ondansetron and 5HT2 antagonist mianserin also enhance analgesic effect of melatonin. ML1 antagonist luzindole did not block but rather enhanced the antinociceptive activity of melatonin, which supported effect of ML2 but not ML1 in pain modulation. Espino et al. [21] found that MT2 receptor antagonist and a selective $\delta$ opioid receptor antagonist completely or partially reduced the antinociceptive effect of melatonin. Thus they draw a different conclusion: MT2 and $\delta$ opioid receptor may play important role in these effects. Tu et al. [23] agreed with MT2 receptors analgesic role in capsaicin inflammatory pain. These opposing results of endogenous/exogenous melatonin implicated that might be disparate pathway of melatonin. Is it possible that in low(physiological) dosage, melatonin mainly acts on membrane receptors, while in higher (pharmacological) dosage, nuclear receptors or other receptors also be activated which might lead to different pathway?

\subsection{Melatonin in Neuropathic Pain}

Neuropathic pain is generally accepted to be chronic and particularly insensitive to drug treatment. Hyperalgesic and allodynic are two common symptoms along with neuropathic pain. Most experiments supported analgesic and antihyperalgesic effect of melatonin in neuropathic pain [24] [25]. Whether melatonin could manage allo- 
dynic has not got an accordant answer [24]-[26]. Mocina et al. [24] reported that intrathecal (3 - 100 microg) and oral (37.5 - $300 \mathrm{mg} / \mathrm{kg})$ administration of melatonin decreased tactile allodynia in rats induced by spinal nerve ligation, while intrathecal/oral administration of MT2 and opioid receptors antagonist dismissed antiallodynic effect of melatonin in a dose-dependent manner. However, Ahmet et al. [25] reported that intraperitoneal $(30,60,120 \mathrm{mg} / \mathrm{kg})$ and intracerebroventricular $(0.001,0.01,0.1 \mathrm{nmol})$ melatonin exerted its antihyperalgesic effect but not antiallodynia in mice through larginine-Nitric oxide pathway and opioid system. Assumed that hyperalgesic and allodynic were mediated by different nerve fibers and melatonin was more sensitive to small diameter unmyelinated high threshold C-fiber. Interestingly, Zurowski D. et al. [26] reported opposite result that intraperitoneal administration (100 mg/kg) of exogenous melatonin abolished mechanical allodynia but not thermal hyperalgesia in rat chronic constriction injury. And this effect could be almost blunted by nonselective opioid receptor antagonist naloxone and MT1/MT2 antagonist luzindole. They thought the influence of melatonin on the process of thermal hyperalgesia is based rather on its anti-inflammatory effect than on the opioid system activation. Rayleigh Ping et al. [27] reported that in rats melatonin dose-dependently improved behavioral hypersensitivity by attenuating p-p38 MAPK levels and release of proinflammatory cytokines; meanwhile, pinealectomy which caused a reduction in endogenous melatonin levels exacerbated these effects. All these conflicting results did implicate that various and complex mechanisms of melatonin involved in pain modulation.

\section{Possible Pathways of Melatonin in Pain Modulation}

The precise modes of action of melatonin in pain regulation are not completely understood. Evidences from libratory and clinic suggest many systems, like opioid system, N-methyl-D-aspartate (NMDA), Nitric-oxide (NO) pathway, etc. play a role in melatonin pain modulatory effect [24] [25] [28]. Since melatonin can penetrate the blood-brain-barrier due to high lipid solubility and wide distribution of melatonin binding site throughout CNS, prompts central nociceptive regulation of melatonin [7]. The fact that central administration of melatonin exerts effect in much lower dosage ( $\mu \mathrm{g}$ ) when comparing to systemic administration (mg) supports a central modulation mode at some degree [11] [24]. Aaron et al. [29] found that melatonin acts at supraspinal sites at least in model of post-inflammatory visceral hyperalgesia. Yet, peripheral nociceptive regulatory effect could not be ignored either [11]. It might be due to anti-inflammatory action of melatonin through inhibition of COX-2 and iNOS [30].

\subsection{Melatonin Receptor}

A great numbers of experiments suggested that MT1/MT2 receptor played important roles in pain modulation. As high affinity $G$ protein-coupled receptors, they influenced various systems, like opioid system, adrenergic system, second messenger system, etc. thus to modulate pain [21] [24] [25]. Zahn et al. [7] found that great majority functional melatonin receptor subtype represented in spinal cord of rat was MT1 receptor but not MT2,in spite of evidences suggested MT2 melatonin receptor worked in melatonin analgesic effect [21] [24]. The relation between MT1/MT2 receptors in pain modulation called for more researches. And it prudent to be noted that melatonin nuclear receptor RZR/ROR enhanced IL-2 and IL-6 production which were important cytokine in inflammation in human B cell [31], conversely melatonin improve inflammatory by inhibiting the release of proinflammatory cytokines [30]. Was it possible that activation of melatonin membrane/nuclear respectively would lead to different pathway of pain modulation? Further investigations were needed to determine role of $\mathrm{RZR} / \mathrm{ROR}$ receptor in pain modulation.

\subsection{Opioid System}

Most researches suggested opioid system closely related to analgesic effect of melatonin. Based on the fact that opioid antagonist reduced melatonin analgesic effect and interaction between melatonin and important endogenous opioid, $\beta$-endorphin [25] [26] [32]. But controversy still existed. Shavali et al. [32] reported that melatonin increased the release of $\beta$-endorphin through its receptors instead of direct binding to opioid receptor. However, Barrett et al. [33] reported that functional pinealectomy which suppressed melatonin secretion led to elevated level of $\beta$-endorphin. Besides, it should be noted that pineal opioid axis might be bidirection. Feedback between melatonin opioid system might affect pain modulation [34]. Moreover, it was interesting to found that morphine induced dose-related opposite peripheral actions. Peripheral nociceptor stimulation in low dosage 
while peripheral antinociception by higher dosage [35]. It suggested dual pain modulatory effect of opioid system. Would this effect contributed to dual pain modulation of melatonin needed further study.

\subsection{Nitric-Oxide}

Nitric-oxide (NO) as a second message involved in neuroprotection, neurotoxicity, neurotransmission, and neuroplasticity also played an important role [36]. Evidences suggested that melatonin was able to modulate NO. Esposoto et al. [37] showed that melatonin was able to blocked protein nitration affecting inducible nitric-oxide synthase (iNOS) expression in paw tissue thus to improve tissue damage and inflammation. Result of Alfonso et al. [25] suggested NO involved in pain modulation of melatonin in formalin test through NO-cyclic GMP-protein kinase G-K+ channels pathway. Interestingly, as Kawabata et al. [38] reported NO showed a dual role (analgesic/proalgesic) in pain modulation in different dosages. Callsen-Cencic, P. et al. [36] thought that spinal neuronal nitric oxide synthase expression critically depend on the type of afferent fibers activated by a specific lesion as well as the intensity and duration of input to the spinal cord. A recent review concludes complex pain modulatory action of NO [39]. The dual effect of NO in pain modulation might explain the conflicting results of melatonin in different experiments to some extent.

\subsection{N-Methyl-D-Aspartate (NMDA) Receptor}

NMDA receptor was another important factor involved in pain modulation of melatonin, especially in peripheral and central sensitization [20]. Evidences showed that spinal cord synaptic potentiation phenomenon called windup activity was significant in the development and maintenance of chronic pain and pain transmission which NMDA receptor plays an important role in spinal wind-up effect [40]-[42]. Noseda et al. [41] reported that melatonin it induced dose dependent inhibition of wind-up activity. And this effect could be attenuated by MT receptor antagonist luzindole. It is corroborated by experimental result of Laurido et al. [42] and Mauricio et al. [40]. Wang et al. [28] reported that melatonin improved mechanical hyperalgesia and depressive behaviors, down-regulated NR1 subunit of the NMDA receptor in rat TMJ inflammatory model. Furthermore, melatonin decreased NMDA-induced currents in spinal cord dorsal horn substantia gelatinosa neurons dose-dependently in patch-clamp recordings.

\section{Conclusions}

On the whole, exogenous melatonin showed antinociceptive action in most studies, and melatonin receptor, opioid system, NO, etc., were involved in this action. Effect of endogenous melatonin in pain modulation demands further investigation. Exact composition of experimental conditions like dosage of melatonin, pain model, etc. appears to influence analgesic/proalgesic action of melatonin. Melatonin nuclear receptor, opioid system, dual effect of NO, etc. might be factors leading to opposing pain modulatory effect of melatonin in various settings.

Two factors might explain the divergence of views: first, most researches studied effect of exogenous melatonin, which employed high pharmacological dosage (mg) far beyond physiological dosage (pg) of melatonin. The possibility that different dosages of melatonin might exert opposite effect through different pathways could not be excluded. Second, different experimental designs including animal species, pain tests and behavioral endpoints, season, etc. would lead to opposing finding [10] [14]. For these might influence sensitivity to melatonin or pain processing pathways.

\section{Acknowledgements}

This review was supported by the National Natural Science Foundation of China (No. 81371107) and the Science Technology Program of Guangdong (No. S201301005888).

\section{References}

[1] Srinivasan, V., Lauterbach, E.C., Ho, K.Y., Acuña-Castroviej, D., Zakaria, R. and Brzezinski, A.(2012) Melatonin in Antinociception: Its Therapeutic Application. Current Neuropharmacology, 10, 167-178. http://dx.doi.org/doi:10.2174/157015912800604489

[2] Srinivasan, V., Pandi-Perumal, S.R., Spence, D.W., Mos-covitch, A., Trakht, I., Brown, G.M. and Cardinali, D.P. (2010) Potential Use of Melatonergic Drugs in Analgesia: Mechanisms of Action. Brain Research Bull, 81, 362-371. 
http://dx.doi.org/doi:10.1016/j.brainresbull.2009.12.001

[3] Carlberg, C. (2000) Gene Regulation by Melatonin. Annals of the New York Academy of Sciences, New York, 917, $387-396$.

[4] Williams, L.M., Hannah, L.T., Hastings, M.H. and Maywood, E.S. (1995) Melatonin Receptors in the Rat Brain and Pituitary. Journal of Pineal Research, 19, 173-177. http://dx.doi.org/10.1016/0304-3940(94)90532-0

[5] Wan, Q. and Pang, S.F. (1994) Segmental, Coronal and Subcellular Distribution of 2-[125I]iodomelatonin Binding Sites in the Chicken Spinal Cord. Neuroscience Letters, 180, 253-256. http://dx.doi.org/10.1016/0304-3940(94)90532-0

[6] Wan, Q., Liao, M., Brown, G.M. and Pang, S.F. (1996) Localization and Characterization of Melatonin Receptors in the Rabbit Spinal Cord. Neuroscience Letters, 204, 77-80. http://dx.doi.org/10.1016/0304-3940(96)12321-1

[7] Zahn, P.K., Lansmann, T., Berger, E., Speckmann, E.J. and Musshoff, U.(2003) Gene Expression and Functional Characterization of Melatonin Receptors in the Spinal Cord of the Rat: Implications for Pain Modulation. Journal of Pineal Research, 35, 24-31. http://dx.doi.org/10.1034/j.1600-079x.2003.00047.x

[8] Ray, M., Mediratta, P.K., Mahajan, P. and Sharma, K.K. (2004) Evaluation of the Role of Melatonin in Formalin-Induced Pain Response in Mice. Indian Journal of Medical Science, 58, 122-130.

[9] Perissin, L., Boccalon, S., Scaggiante, B., Petrelli, L., Ortolani, F. and Porro, C.A. (2004) Diurnal Changes of Tonic Nociceptive Responses in Mice: Evidence for a Proalgesic Role of Melatonin. Pain, 110, 250-258. http://dx.doi.org/10.1016/s0304-3959(04)00181-2

[10] Perissin, L., Facchin, P. and Porro, C.A. (2003) Tonic Pain Response in Mice: Effects of Sex, Season and Time of Day. Life Science, 72, 897-907. http://dx.doi.org/10.1016/s0024-3205(02)02344-5

[11] Wang, S., Zhang, L., Lim, G., Sung, B., Tian, Y., Chou, C.W., Hernstadt, H., Rusanescu, G., Ma, Y. and Mao, J.A. (2009) Combined Effect of Dextromethorphan and Melatonin on Neuropathic Pain Behavior in Rats. Brain Research, 1288, 42-49. http://dx.doi.org/doi: 10.1016/j.brainres.2009.06.094

[12] Ambriz-Tututi, M. and Granados-Soto, V. (2007) Oral and Spinal Melatonin Reduces Tactile Allodynia in Rats via Activation of MT2 and Opioid Receptors. Pain, 132, 173-280. http://dx.doi.org/10.1016/j.pain.2007.01.025

[13] Ulugol, A., Dokmeci, D., Guray, G., Sapolyo, N., Ozyiqit, F. and Tamer, M. (2006) Antihyperalgesic, but Not Antiallodynic, Effect of Melatonin in Nerve-Injured Neuropathic Mice: Possible Involvements of the Larginine-NO Pathway and Opioid System. Life Science, 78, 1592-1597. http://dx.doi.org/10.1016/j.lfs.2005.07.002

[14] Perissin, L., Facchin, P. and Porro, C.A. (2006) Diurnal Variations in Tonic Pain Reactions in Mice. Life Science, 67, 1477-1488. http://dx.doi.org/10.1016/s0024-3205(00)00733-5

[15] John, T.M., Brown, M.C., Wideman, L. and Brown, G.M. (1994) Melatonin Replacement Nullifies the Effect of LightInduced Functional Pinealectomy on Nociceptive Rhythm in the Rat. Physiological Behavior, 55, 735-739. http://dx.doi.org/10.1016/0031-9384(94)90053-1

[16] Bar-Or, A. and Brown, G.M. (1989) Pineal Involvement in the Diurnal Rhythm of Nociception in the Rat. Life Science, 44, 1067-1075. http://dx.doi.org/10.1016/0024-3205(89)90333-0

[17] Bachmann, C.G., Nitsche, M.A., Pfingsten, M., Gersdorff, N., Harder, C., Baier, P.C., Antal, A., Treede, R.D., Paulus, W. and Happe, S. (2011) Diurnal Time Course of Heat Pain Perception in Healthy Humans. Neuroscience Letters, 489, 122-125. http://dx.doi.org/10.1016/j.neulet.2010.11.080

[18] Wilhelmsen, M., Amirian, I., Reiter, R.J., Rosenberg, J. and Gögenur, I. (2011) Analgesic Effects of Melatonin: A Review of Current Evidence from Experimental and Clinical Studies. Journal of Pineal Research, 51, 170-177. http://dx.doi.org/10.1111/j.1600-079x.2011.00895.x

[19] Makay, B. (2009) Is There a Role of Melatonin in the Development of Growing Pains? Medical Hypotheses, $72,225$. http://dx.doi.org/10.1016/j.mehy.2008.09.028

[20] Costigan, M. and Woolf, C.J. (2000) Pain: Molecular Mechanisms. Journal of Pain, 1, 35-44.

[21] Arreola-Espino, R., Urquiza-Marín, H., Ambriz-Tututi, M., Araiza-Saldaña, C.I., Caram-Salas, N.L., Rocha-González, H.I., Mixcoatl-Zecuati, T. and Granados-Soto, V. (2007) Melatonin Reduces Formalin-Induced Nociception and Tactile Allodynnia in Diabetic Rats. European Journal of Pharmacology, 577, 203-210. http://dx.doi.org/10.1016/j.ejphar.2007.09.006

[22] Huang, F., He, H.W., Fan, W.G., Liu, Y.L., Zhou, H.Y. and Cheng B. (2013) Orofacial Inflammatory Pain Affects the Expression of MT1 and NADPH-d in Rat Caudal Spinal Trigeminal Nucleus and Trigeminal Ganglion. Neural Regeneration Research, 8, 2991-3002.

[23] Tu, Y., Sun, R.Q. and Willis, W.D. (2004) Effects of Intrathecal Injections of Melatonin Analogs on Capsacin-Induced Secondary Mechanical Allodynia and Hyperalgesia in Rats. Pain, 109, 340-350. http://dx.doi.org/10.1016/j.pain.2004.01.027

[24] Ambriz-Tututi, M. and Granados-Soto, V. (2007) Oral and Spinal Melatonin Reduces Tactile Allodynia in Rats via Activation of $\mathrm{MT}_{2}$ and Opioid Receptors. Pain, 132, 173-280. http://dx.doi.org/10.1016/j.pain.2007.01.025 
[25] Ulugol, A., Dokmeci, D., Guray, G., Sapolyo, N., Ozyiqit, F. and Tamer, M. (2006) Antihyperalgesic, but Not Antiall-Odynic, Effect of Melatonin in Nerve-Injured Neuropathic Mice: Possible Involvements of the L-Arginine-NO Pathway and Opioid System. Life Sciences, 78, 1592-1597. http://dx.doi.org/10.1016/j.lfs.2005.07.002

[26] Zurowski, D., Nowak, L., Machowska, A., Wordliczek, J. and Thor, P.J. (2012) Exogenous Melatonin Abolishes Mechanical Allodynia but Not Thermal Hyperalgesia Inneuropathic Pain. The Role of the Opioid System and Benzodiazepine-Gabaergic Mechanism. Journal of Physiology and Pharmacology, 63, 641-647.

[27] Chiang, R.P., Huang, C.T. and Tsai, Y.J. (2013) Melatonin Reduces Median Nerve Injury-Induced Mechanical Hypersensitivity via Inhibition of Microglial p38 Mitogen-Activated Protein Kinase Activation in Rat Cuneate Nucleus. Journal of Pineal Research, 54, 232-244. http://dx.doi.org/10.1111/jpi.12029

[28] Wang, S., Tiana, Y., Song, L., Lim, G., Tan, Y., You, Z., Chen, L. and Mao, J. (2012) Exacerbated Mechanical Hyperalgesia in Rats with Genetically Predisposed Depressive Behavior: Role of Melatonin and NMDA Receptors. Pain, 153, 2448-2457. http://dx.doi.org/10.1016/j.pain.2012.08.016

[29] Mickle, A., Sood, M., Zhang, Z., Shahmohammadi, G., Sengupta, J.N. and Miranda, A. (2010) Antinociceptive Effects of Melatonin in a Rat Model of Post-Inflammatory Visceral Hyperalgesia: A Centrally Mediated Process. Pain, 149, 555-564. http://dx.doi.org/10.1016/j.pain.2010.03.030

[30] Mayo, J.C., Sainz, R.M., Tan, D.X., et al. (2005) Anti-Inflammatory Actions of Melatonin and Its Metabolites, $\mathrm{N}_{1}$-Acetyl- $\mathrm{N}_{2}$-formyl-5-methoxykynuramine (AFMK) and $\mathrm{N}_{1}$-Acetyl-5-methoxykynuramine (AMK), in Macrophages. Journal of Neuroimmunology, 165, 139-149. http://dx.doi.org/10.1016/j.jneuroim.2005.05.002

[31] Carrillo-Vico, A., Lardone, P.J., Fernandez-Santos, J.M., Martin-Lacave, I., Calvo, J.R., Karasek, M. and Guerrero, J.M. (2005) Human Lymphocyte Synthesized Melatonin Is Involved in the Regulation of the Interlekin-2/Interleukin-2 Receptor System. Journal of Clinical Endocrinology \& Metabolism, 90, 992-1000. http://dx.doi.org/10.1210/jc.2004-1429

[32] Shavali, S., Ho, B., Govitrapong, P., Sawlom, S., Aijimaporn, A., Klongpanichapak, S. and Ebadi, M. (2005) Melatonin Exerts Its Analgesic Actions Not by Binding to Opioid Receptor Subtypes but by Increasing the Release of $\beta$-endorphin an Endogenous Opioid. Brain Research Bulletin, 64, 471-479. http://dx.doi.org/10.1016/j.brainresbull.2004.09.008

[33] Barrett, T., Kent, S. and Voudouris, N. (2000) Does Melatonin Modulate Beta-Endorphin, Corticosterone, and Pain Threshold? Life Sciences, 66, 467-476. http://dx.doi.org/10.1016/s0024-3205(99)00616-5

[34] Ebadi, M., Govitrapong, P., Phansuwan-Pujito, P., Nelson, F. and Reiter, R.J. (1998) Pineal Opioid Receptors and Analgesic Action of Melatonin. Journal of Pineal Research, 24, 193-200. http://dx.doi.org/10.1111/j.1600-079x.1998.tb00532.x

[35] Ono, T., Inoue, M., Rashid, M.H., Sumikawa, K. and Ueda, H. (2002) Stimulation of Peripheral Nociceptor Endings by Low Dose Morphine and Its Signaling Mechanism. Neurochemistry International, 41, 399-407. http://dx.doi.org/10.1016/s0197-0186(02)00047-5

[36] Callsen-Cencic, P., Hoheisel, U., Kaske, A., Mense, S. and Tenschert, S. (1999) The Controversy about Spinal Neuronal Nitric Oxide Synthase: Under Which Conditions Is It Up or Downregulated? Cell and Tissue Research, 295, 183-194. http://dx.doi.org/10.1007/s004410051224

[37] Esposito, E., Paterniti, I., Mazzon, E., Bramanti, P. and Cuzzoreca, S. (2010) Melatonin Reduces Hyperalgesia Associated with Inflammation. Journal of Pineal Research, 49, 321-331. http://dx.doi.org/10.1111/j.1600-079x.2010.00796.x

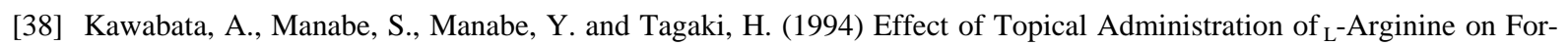
malin-Induced Nociception in the Mouse: A Dual Role of Peripherally Formed NO in Pain Modulation. British Journal of Pharmacology, 112, 547-550. http://dx.doi.org/10.1111/j.1476-5381.1994.tb13108.X

[39] Cury, Y., Picolo, G., Gutierrez, V.P. and Ferreira, S.H. (2011) Pain and Analgesia: The Dual Effect of Nitric Oxide in the Nociceptive System. Nitric Oxide, 25, 243-254. http://dx.doi.org/10.1016/j.niox.2011.06.004

[40] Mondaca, M., Hernández, A., Valladares, L., Sierralta, W., Noseda, R. and Soto-Moyano, R. (2004) Involvement of Melatonin Metabolites in the Long-Term Inhibitory Effect of the Hormone on Rat Spinal Nociceptive Transmission. Pharmacology Biochemistry and Behavior, 77, 275-279. http://dx.doi.org/10.1016/j.pbb.2003.11.007

[41] Noseda, R., Hernandez, A., Valladare, L., Mondaca, M., Laurido, C. and Soto-Moyano, R. (2004) Melatonin-Induced Inhibition of Spinal Cord Synaptic Potentiation in Rats is $\mathrm{MT}_{2}$ Receptor-Dependent. Neurosciebce Letters, 360, 41-44. http://dx.doi.org/10.1016/j.neulet.2004.01.080

[42] Laurido, C., Pelissie, T., Soto-Moyano, R., Valladares, L., Flores, F. and Hernández, A. (2002) Effect of Melatonin on Rat Spinal Cord Nociceptive Transmission. Neuroreport, 13, 89-91. http://dx.doi.org/10.1097/00001756-200201210-00021 